\title{
18F-THK5351: A Novel PET Radiotracer for Imaging Neurofibrillary Pathology in Alzheimer Disease
}

\author{
Ryuichi Harada ${ }^{1}$, Nobuyuki Okamura ${ }^{1-3}$, Shozo Furumoto ${ }^{4}$, Katsutoshi Furukawa ${ }^{5}$, Aiko Ishiki ${ }^{5}$, Naoki Tomita ${ }^{5}$, \\ Tetsuro Tago ${ }^{4}$, Kotaro Hiraoka ${ }^{3}$, Shoichi Watanuki ${ }^{3}$, Miho Shidahara ${ }^{3,6}$, Masayasu Miyake ${ }^{3}$, Yoichi Ishikawa ${ }^{4}$, \\ Rin Matsuda ${ }^{3}$, Akie Inami ${ }^{3}$, Takeo Yoshikawa ${ }^{2}$, Yoshihito Funaki ${ }^{4}$, Ren Iwata ${ }^{4}$, Manabu Tashiro ${ }^{3}$, Kazuhiko Yanai ${ }^{2}$, \\ Hiroyuki Arai ${ }^{5}$, and Yukitsuka Kudo ${ }^{1,4}$

\begin{abstract}
${ }^{I}$ Division of Neuro-imaging, Institute of Development, Aging and Cancer, Tohoku University, Sendai, Japan; ${ }^{2}$ Department of Pharmacology, Tohoku University School of Medicine, Sendai, Japan; ${ }^{3}$ Division of Cyclotron Nuclear Medicine, Cyclotron and Radioisotope Center, Tohoku University, Sendai, Japan; ${ }^{4}$ Division of Radiopharmaceutical Chemistry, Cyclotron and Radioisotope Center, Tohoku University, Sendai, Japan; ${ }^{5}$ Department of Geriatrics and Gerontology, Institute of Development, Aging and Cancer, Tohoku University, Sendai, Japan; and ${ }^{6}$ Division of Medical Physics, Tohoku University School of Medicine, Sendai, Japan
\end{abstract}

\begin{abstract}
Imaging of neurofibrillary pathology in the brain helps in diagnosing dementia, tracking disease progression, and evaluating the therapeutic efficacy of antidementia drugs. The radiotracers used in this imaging must be highly sensitive and specific for tau protein fibrils in the human brain. We developed a novel tau PET tracer, ${ }^{18} \mathrm{~F}-$ THK5351, through compound optimization of arylquinoline derivatives. Methods: The in vitro binding properties, pharmacokinetics, and safety of ${ }^{18} \mathrm{~F}-\mathrm{THK} 5351$ were investigated, and a clinical study on Alzheimer disease (AD) patients was performed. Results: ${ }^{18} \mathrm{~F}-$ THK5351 demonstrated higher binding affinity for hippocampal homogenates from $A D$ brains and faster dissociation from whitematter tissue than did ${ }^{18} \mathrm{~F}$-THK5117. The THK5351 binding amount correlated with the amount of tau deposits in human brain samples. Autoradiography of brain sections revealed that THK5351 bound to neurofibrillary tangles selectively and with a higher signal-tobackground ratio than did THK5117. THK5351 exhibited favorable pharmacokinetics and no defluorination in mice. In first-in-human PET studies in AD patients, ${ }^{18} \mathrm{~F}-\mathrm{THK} 5351$ demonstrated faster kinetics, higher contrast, and lower retention in subcortical white matter than ${ }^{18} \mathrm{~F}-\mathrm{THK} 5117$. Conclusion: ${ }^{18} \mathrm{~F}-\mathrm{THK} 5351$ is a useful PET tracer for the early detection of neurofibrillary pathology in $A D$ patients.
\end{abstract}

Key Words: Alzheimer's disease; tau; PET; radiotracer; ${ }^{18} \mathrm{~F}-\mathrm{THK} 5351$

J Nucl Med 2016; 57:208-214

DOI: 10.2967/jnumed.115.164848

$\mathbf{T}$ au accumulation occurs in a stereotyped spatiotemporal manner at the intraneuronal and anatomic distribution levels in the brain and is associated with neuronal loss and cognitive impairment (1-5). Because tau accumulation plays a key role in neurodegeneration and is considered to start before extensive neuronal loss emerges, tau-focused drug-discovery strategies for Alzheimer

Received Aug. 3, 2015; revision accepted Oct. 22, 2015.

For correspondence or reprints contact: Nobuyuki Okamura, Department of Pharmacology, Tohoku University School of Medicine, 2-1, Seiryo-machi, Aoba-ku, Sendai 980-8575, Japan.

E-mail: nookamura@med.tohoku.ac.jp

Published online Nov. 5, 2015.

COPYRIGHT (C 2016 by the Society of Nuclear Medicine and Molecular Imaging, Inc. disease (AD) are of particular interest (6,7). In efforts to accelerate drug discovery, there is growing demand for techniques to measure brain tau loads noninvasively. PET imaging of tau is expected to provide spatiotemporal information on the progression of tau pathology in the living brain. Therefore, this technique will facilitate accurate tauopathy diagnosis, precise assessment of disease severity and therapeutic efficacy, and patient enrolment for antitau therapeutic trials $(8-10)$.

Several putative tau PET tracers have been developed and tested in humans (11-14), and all of these tracers show elevated uptake in the hippocampus and temporal cortex of $\mathrm{AD}$ patients. We screened $\beta$-sheet-binding compounds and identified a series of compounds that preferentially bind to tau deposits in AD brains (15-17). Through compound optimization, several ${ }^{18}$ F-labeled arylquinoline derivatives were developed as candidate tau PET radiotracers (18). Recent ${ }^{18} \mathrm{~F}$-THK5105 and ${ }^{18} \mathrm{~F}$-THK5117 PET studies demonstrated increased tracer uptake in common sites of tau pathology in AD and its association with clinical severity of dementia $(19,20)$. However, these tracers-like amyloid PET tracers-showed high nonspecific retention in subcortical white matter. This white-matter binding must be minimized because the signals could obscure visual interpretation of PET images and decrease detection sensitivity for early tau pathology in the presymptomatic stage of AD. For assessing the therapeutic efficacy of potential antitau drugs in clinical trials, tau PET tracers must be adequately sensitive to detect even subtle changes in brain tau loads. Moreover, tau PET is expected to detect age-associated neurofibrillary tangles in cognitively normal individuals, recently named primary age-associated tauopathy (21-23). Because such age-related tau pathology is typically milder than disease-related changes in $\mathrm{AD}$, the radiotracers used must be highly sensitive.

To reduce nonspecific tracer retention in white matter and increase the signal-to-background ratio of PET images, we replaced a benzene ring of ${ }^{18} \mathrm{~F}-\mathrm{THK} 5117$ with pyridine and developed a novel tau PET tracer, ${ }^{18} \mathrm{~F}$-THK5351. ${ }^{18} \mathrm{~F}$-THK5351 is a single $S$-enantiomer, which should improve the pharmacokinetics of arylquinoline derivatives (Fig. 1). To evaluate the clinical usefulness of ${ }^{18} \mathrm{~F}$-THK5351 as a tau PET tracer, we examined the in vitro binding properties, pharmacokinetics, and safety of ${ }^{18} \mathrm{~F}-\mathrm{THK} 5351$ and performed a clinical study on $\mathrm{AD}$ patients. 


\section{MATERIALS AND METHODS}

\section{Radiosynthesis of Quinoline Derivatives}

${ }^{18} \mathrm{~F}-\mathrm{THK} 5351$ was prepared from its tosylate precursor $(S)-2-(2-$ methylaminopyrid-5-yl)-6-[[2-(tetrahydro-2H-pyran-2-yloxy)-3-tosyloxy] propoxy] quinoline (THK5352) according to the previously described method for synthesizing ${ }^{18} \mathrm{~F}-\mathrm{THK} 5105$ and ${ }^{18} \mathrm{~F}-\mathrm{THK} 5117$ (18). ${ }^{18} \mathrm{~F}$-THK5351 was purified using semipreparative high-performance liquid chromatography (column: Inertsil ODS-4 [GL Sciences, Inc.]; mobile phase: $20 \mathrm{mmol} / \mathrm{L} \mathrm{NaH} \mathrm{PO}_{4} /$ acetonitrile [75/25 for THK5351]; flow rate: $5.0 \mathrm{~mL} / \mathrm{min}$ ). The radiolabeled product was dissolved in ethanol, dimethylsulfoxide, or saline with polysobate- $80(<0.1 \%)$ for biologic evaluation. ${ }^{18} \mathrm{~F}$-THK5351 was obtained at a radiochemical yield of $46 \% \pm 13 \%$ (decay-corrected), radiochemical purity of greater than $95 \%$, and specific activity of $254 \pm 47 \mathrm{GBq} / \mu \mathrm{mol} .{ }^{3} \mathrm{H}-\mathrm{Pittsburgh}$ compound B (PiB) (specific activity, $2.96 \mathrm{GBq} / \mu \mathrm{mol}$; radiochemical purity, 99\%) was purchased from American Radiolabeled Chemicals. ${ }^{3} \mathrm{H}-$ THK5351 (specific activity, $2.96 \mathrm{TBq} / \mathrm{mmol}$; radiochemical purity, 98.9\%) and ${ }^{3} \mathrm{H}-\mathrm{THK} 5117$ (specific activity, $2.78 \mathrm{TBq} / \mathrm{mmol}$; radiochemical purity, $98.2 \%$ ) were custom-labeled by Sekisui Medical Inc.

\section{In Vitro Binding Study}

Experiments were performed as per the regulations of the Ethics Committee of the Tohoku University School of Medicine. Brain samples were obtained from Tohoku University Brain Bank. The following studies were conducted as previously described: in vitro saturation binding assays (18); in vitro association and dissociation rate measurement $(20,24)$; and in vitro binding assays, using $1 \mathrm{nmol} / \mathrm{L}{ }^{3} \mathrm{H}$-labeled ligands (20).

\section{Autoradiography}

Experimental procedures followed the regulations of the Ethics Committee of the Tohoku University School of Medicine. Autoradiography in postmortem brain sections was conducted using ${ }^{3} \mathrm{H}-\mathrm{THK} 5351$, ${ }^{3} \mathrm{H}-\mathrm{THK} 5117$, and ${ }^{3} \mathrm{H}-\mathrm{PiB}$ as previously reported (20). Washing procedures were modified slightly. Briefly, after 30-min incubation at room temperature with $3 \mathrm{nmol} / \mathrm{L}{ }^{3} \mathrm{H}$-labeled compounds, sections were washed sequentially with phosphate-buffered saline containing $1 \%$ bovine serum albumin $(5 \mathrm{~min})$ and phosphate-buffered saline ( 5 min, twice). Dried sections were exposed to an imaging plate for $3 \mathrm{~d}$. High-resolution autoradiography of ${ }^{3} \mathrm{H}$-labeled sections was performed as before (20).

\section{Small-Animal PET Studies}

All animal experiment protocols were approved by the Laboratory Animal Care Committee of Tohoku University. In vivo PET studies were performed using male SLC:ICR mice, as previously described (24).

\section{Biodistribution Studies}

Biodistribution was investigated after intravenous injection of ${ }^{18} \mathrm{~F}$ THK5351 or ${ }^{18} \mathrm{~F}$-THK5117 into male ICR mice as previously described (18). On the basis of the biodistribution data from mice (percentage injected dose per gram), we estimated the radiation dose and mass dose for humans.

\section{Animal Toxicity Studies}

A 14-d toxicity study involving a single-dose THK5351 test-article administration through intravenous injection in ICR mice was performed at Mitsubishi Chemical Medience Corp., as previously described (18).

\section{Radiosynthesis for Clinical PET Study}

${ }^{18} \mathrm{~F}-\mathrm{THK} 5351,{ }^{18} \mathrm{~F}-\mathrm{THK} 5117$, and ${ }^{11} \mathrm{C}-\mathrm{PiB}$ were prepared at the Cyclotron and Radioisotope Center, Tohoku University. ${ }^{18}$ F-THK5351 was radiosynthesized using a semiautomated system developed in-house. No-carrier-added ${ }^{18} \mathrm{~F}$-fluoride $\left({ }^{18} \mathrm{~F}^{-}\right)$produced by the HM-12 cyclotron
(30 $\mathrm{min} / 25 \mu \mathrm{A}$; Sumitomo Heavy Industries) was separated from the irradiated target water using a Sep-Pak Light Accell Plus QMA cartridge (Waters). The trapped ${ }^{18} \mathrm{~F}^{-}$was eluted using a Kryptofix solution (Kryptofix 222 [20 mg], $\mathrm{K}_{2} \mathrm{CO}_{3}$ [4 mg], $\mathrm{MeCN}$ [0.7 mL], $\mathrm{H}_{2} \mathrm{O}$ [0.3 mL]) into a reaction vial. The solution was evaporated to dryness through azeotropic distillation with acetonitrile. After drying, THK5352 (3 mg, $5.3 \mu \mathrm{mol})$ dissolved in dimethylsulfoxide $(0.7 \mathrm{~mL})$ was transferred into the reaction vial and stirred at $110^{\circ} \mathrm{C}$ for $10 \mathrm{~min}$, and then aqueous $\mathrm{HCl}(2 \mathrm{~mol} / \mathrm{L}$, $0.2 \mathrm{~mL}$ ) was added to the reaction solution and stirred at $110^{\circ} \mathrm{C}$ for another $3 \mathrm{~min}$. The reaction was then quenched with aqueous AcOK $(0.8 \mathrm{~mol} / \mathrm{L}, 1 \mathrm{~mL})$ and distilled water $(7 \mathrm{~mL})$, after which solid-phase extraction was performed using a Sep-Pak tC18 Plus cartridge (Waters). The trapped radioactive products were eluted using $60 \% \mathrm{EtOH}$, and then the eluate was mixed with $\mathrm{H}_{2} \mathrm{O}$ and subjected to semipreparative high-performance liquid chromatography separation under the same conditions as those described above. The high-performance liquid chromatography fraction of ${ }^{18} \mathrm{~F}-\mathrm{THK} 5351$ was collected in glassware containing $\mathrm{H}_{2} \mathrm{O}(30 \mathrm{~mL})$ and ascorbic acid $(25 \%, 1.0 \mathrm{~mL}$; NIPRO Pharma), and ${ }^{18} \mathrm{~F}-\mathrm{THK} 5351$ was isolated from the solution through solid-phase extraction performed using a Sep-Pak tC18 Plus cartridge. The ethanol eluate from the cartridge was transferred into a flask containing polysorbate-80 $(5 \%$ in ethanol, $0.8 \mathrm{~mL})$ and ascorbic acid $(25 \%, 0.2 \mathrm{~mL})$, and then the solution was evaporated to dryness. The radioactive residue was dissolved in saline and sterilized through filtration using a Millex-GV Syringe Filter Unit (Millipore). ${ }^{18} \mathrm{~F}$ THK5117 was synthesized as previously described (20). ${ }^{11} \mathrm{C}-\mathrm{PiB}$ was synthesized using a loop-method with ${ }^{11} \mathrm{C}$-methyl triflate, as previously reported (25). The radiochemical purity of the injectable solutions of ${ }^{18} \mathrm{~F}$ THK5351, ${ }^{18} \mathrm{~F}-\mathrm{THK} 5117$, and ${ }^{11} \mathrm{C}-\mathrm{PiB}$ was greater than $95 \%$, and their specific activities were $254 \pm 47,357 \pm 270$, and $240 \pm 48 \mathrm{GBq} / \mu \mathrm{mol}$, respectively.

\section{Clinical PET Study Participants}

Three AD patients and 3 healthy elderly study participants underwent ${ }^{18}$ F-THK5351 PET scans. Participant demographic data are shown in Supplemental Table 1 (supplemental materials are available at http:// jnm.snmjournals.org). Two $\mathrm{AD}$ patients underwent additional ${ }^{18} \mathrm{~F}$ THK5117 PET scans within 2-wk intervals and additional ${ }^{11} \mathrm{C}-\mathrm{PiB}$ PET scans within 3-mo intervals. Probable AD was diagnosed on the basis of criteria from the National Institute of Neurologic and Communicative Disorders and Stroke and the Alzheimer Disease Related Disorders Association. This study was approved by the Ethics Committee of the Tohoku University Hospital. The study was fully described to the patients, and then written informed consent was obtained from the patients or their guardians.

\section{PET and MR Image Acquisition}

PET imaging was performed using an Eminence STARGATE PET scanner (Shimadzu). After intravenous injection of ${ }^{18} \mathrm{~F}-\mathrm{THK} 5117$ (185 MBq), ${ }^{18} \mathrm{~F}-\mathrm{THK} 5351$ (185 MBq), or ${ }^{11} \mathrm{C}-\mathrm{PiB}$ (296 MBq), dynamic PET images were obtained for $90 \mathrm{~min}\left({ }^{18} \mathrm{~F}-\mathrm{THK} 5117\right.$ and ${ }^{18} \mathrm{~F}$ THK5351) or $70 \mathrm{~min}\left({ }^{11} \mathrm{C}-\mathrm{PiB}\right)$, with the patients' eyes closed. MRI was performed on all participants. T1- and T2-weighted MR images were obtained using a SIGNA 1.5-T machine (GE Healthcare). In T1-weighted MRI, a 3-dimensional volumetric acquisition of a T1weighted gradient echo sequence produced a gapless series of thin axial sections using a vascular time-of-flight spoiled gradient recalled echo sequence (echo time/repetition time, 2.4/50 ms; flip angle, $45^{\circ}$; acquisition matrix, $256 \times 256 ; 1$ excitation; field of view, $22 \mathrm{~cm}$; slice thickness, $2.0 \mathrm{~mm}$ ).

\section{Image Analysis}

SUV images of ${ }^{18} \mathrm{~F}-\mathrm{THK} 5117,{ }^{18} \mathrm{~F}-\mathrm{THK} 5351$, and ${ }^{11} \mathrm{C}$-PiB were obtained by normalizing tissue radioactivity concentration by injected 


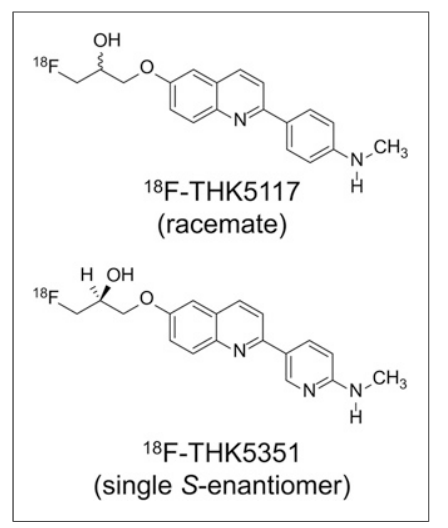

FIGURE 1. ${ }^{18} \mathrm{~F}-$ THK5351 and ${ }^{18} \mathrm{~F}-$ THK5117 chemical structures. dose and body weight. MRI T1 images were coregistered to the early PET images (0-10 min after injection) for each participant using statistical parametric-mapping software (SPM8; Wellcome Department of Imaging Neuroscience, UCL). PET images were processed using a semiautomatic region-of-interest method, as previously described (19). The regional SUV to cerebellar cortex SUV ratio (SUVR) was used as an index of tracer retention. Coregistered MR and PET images were spatially normalized to an MRI T1 template in Talairach space using SPM8. After spatial normalization, regional SUVs were sampled using PMOD software (PMOD Technologies). Regions of interest were placed on individual axial images in the cerebellar hemisphere, dorsolateral prefrontal cortex (Brodmann's area [BA] 9), ventrolateral prefrontal cortex (BA 10, 44, 45, and 46), orbitofrontal cortex (BA 11 and 12), superior temporal cortex (BA 22), inferior temporal cortex (BA 20 and 37), parietal cortex (BA 39 and 40), occipital cortex (BA 17, 18, and 19), anterior cingulate cortex, posterior cingulate cortex, parahippocampal gyrus, and subcortical white matter.

\section{Statistical Analysis}

Pearson correlation coefficients were calculated to access the relationship between ${ }^{3} \mathrm{H}$-labeled tracer binding and the amounts of insoluble protein. Spearman correlation coefficients were calculated to access the relationship between tracer retentions in $\mathrm{AD}$ patients.

\section{RESULTS}

\section{In Vitro Tracer Binding to Human Brain Tissues}

In vitro saturation binding assays were conducted to measure the binding affinity of ${ }^{18} \mathrm{~F}$-THK5351 for postmortem tissues from $\mathrm{AD}$ patients. Scatchard analysis indicated 1-site binding of ${ }^{18} \mathrm{~F}-$ THK5351 for postmortem hippocampal homogenates from an AD patient (Supplemental Fig. 1A). ${ }^{18}$ F-THK5351 bound to AD hippocampal homogenates with high affinity $\left(K_{\mathrm{d}}=2.9 \mathrm{nmol} / \mathrm{L}\right.$; maximum number of binding sites $=368.3 \mathrm{pmol} / \mathrm{g}$ tissue). We measured the in vitro binding of ${ }^{3} \mathrm{H}$-labeled THK5351 and THK5117 to postmortem tissues from $8 \mathrm{AD}$ patients to compare the amount of specific binding of these tracers; the tracers were used at $1 \mathrm{nmol} / \mathrm{L}$, the concentration typically achieved during PET scans. The specific binding of THK5351 and THK5117 was highly correlated $(r=0.98, P<$ 0.0001) (Supplemental Fig. 1B). The specific binding of THK5351 was also correlated with the level of insoluble tau $(r=0.71, P<$ $0.05)$ but not insoluble amyloid- $\beta(r=-0.20, P=0.63)$ or $\mathrm{PiB}(r=$ $-0.10, P=0.82)$, as observed for THK5117 (20). Furthermore, in vitro dissociation assays performed using brain white-matter homogenates revealed that THK5351 dissociated from white matter more rapidly than THK5117 did (Fig. 2A).

\section{In Vitro Autoradiography in Human Brain Sections}

To further evaluate binding selectivity and signal-to-background ratio, in vitro autoradiography was performed using ${ }^{3} \mathrm{H}-\mathrm{THK} 5351$ and ${ }^{3} \mathrm{H}$-THK5117 exhibiting similar specific activity; here, postmortem brain sections from a control participant and AD patients were used. Both ${ }^{3} \mathrm{H}$-THK5351 and ${ }^{3} \mathrm{H}$-THK5117 bound to the gray matter of $\mathrm{AD}$ brain sections in a laminar fashion, which corresponded to tau immunohistochemistry. However, in contrast to the substantial white-matter binding of ${ }^{3} \mathrm{H}$-THK5117, only weak ${ }^{3} \mathrm{H}$-THK5351 signals were detected in white matter (Fig. 2B). ${ }^{3} \mathrm{H}-$ THK5351 showed a higher cortical-to-white-matter binding ratio than ${ }^{3}$ H-THK5117 did (Fig. 2C). ${ }^{3}$ H-THK5351 also showed little binding to control brain sections. Microautoradiography of $\mathrm{AD}$ brain sections provided additional evidence supporting the ability of ${ }^{3} \mathrm{H}$-THK5351 to selectively label neurofibrillary tangles. The ${ }^{3} \mathrm{H}-\mathrm{THK} 5351$ labeling patterns resembled the Gallyas-Braak staining in adjacent sections (Fig. 3). However, ${ }^{3} \mathrm{H}-\mathrm{THK} 5351$ did not label amyloid plaques that were labeled with ${ }^{3} \mathrm{H}-\mathrm{PiB}$ in an adjacent section. Furthermore, autoradiography of hemibrain sections from an $\mathrm{AD}$ patient demonstrated preferential ${ }^{3} \mathrm{H}$-THK5351 binding in the gray matter of the hippocampus, parahippocampal gyrus, fusiform gyrus, inferior and middle temporal gyri, insula, and cingulate gyrus, regions that contain a high density of tau deposits in $\mathrm{AD}$ (Supplemental Fig. 2). These tracer-binding patterns differed completely from the broad neocortical binding of ${ }^{11} \mathrm{C}-\mathrm{PiB}$.

\section{Pharmacokinetics in Mice}

Brain pharmacokinetics of ${ }^{18} \mathrm{~F}$-THK5351 in normal mice were investigated using a small-animal PET scanner. Although the peak brain uptake of ${ }^{18} \mathrm{~F}-\mathrm{THK} 5351$ was slightly lower than that of ${ }^{18} \mathrm{~F}$-THK5117, ${ }^{18} \mathrm{~F}$-THK5351 entered the brain immediately after intravenous injection and showed faster washout from the brain than ${ }^{18} \mathrm{~F}-\mathrm{THK} 5117$ did (Fig. 4; Supplemental Table 2). No marked radiotracer retention in bone was observed after ${ }^{18} \mathrm{~F}$-THK5351 was injected into mice.

\section{Animal Acute-Toxicity Studies}

At 0.1 and $1 \mathrm{mg} / \mathrm{kg}$ dosages under our study conditions, no animals died and no treatment-related changes in any animal were

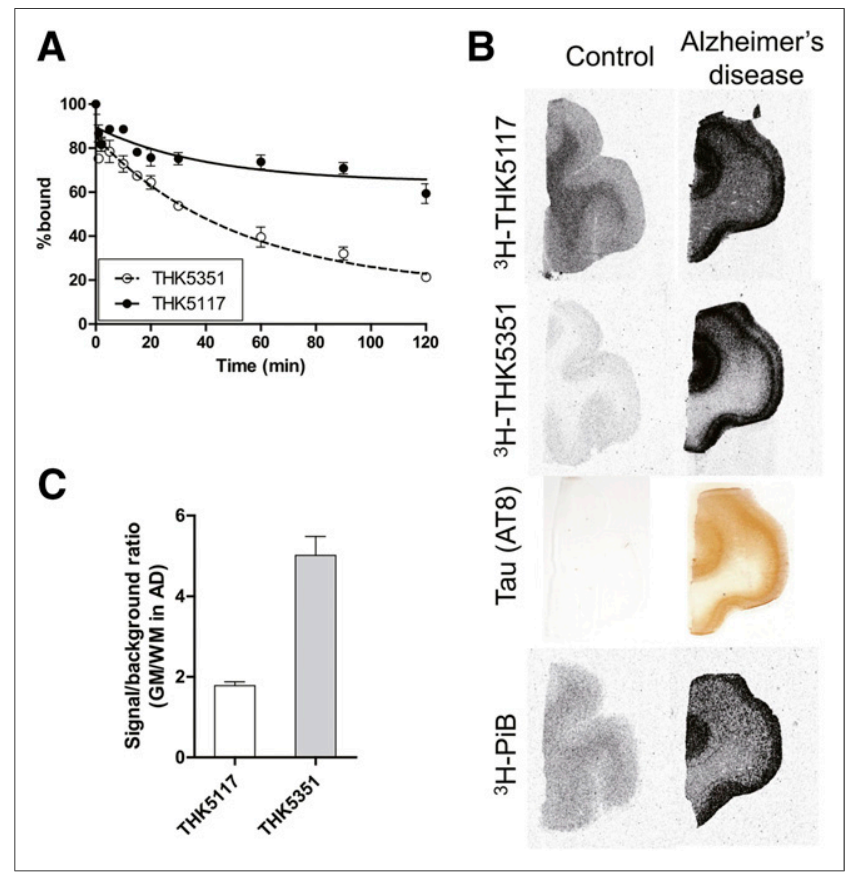

FIGURE 2. (A) In vitro dissociation of ${ }^{18} \mathrm{~F}-$ THK5351 and ${ }^{18} \mathrm{~F}-\mathrm{THK} 5117$ from white-matter homogenates from normal brain. (B) Autoradiography of ${ }^{3} \mathrm{H}-\mathrm{THK} 5117,{ }^{3} \mathrm{H}-\mathrm{THK} 5351$, and ${ }^{3} \mathrm{H}-\mathrm{PiB}$ and tau (AT8) immunostaining in frontal brain sections from control participant and AD patient. (C) Signal-tobackground ratios of ${ }^{3} \mathrm{H}$-labeled THK tracers in sections from AD patient (Braak stage V). Signal-to-background ratio was calculated as intensity of tracer binding in gray matter divided by that in subcortical white matter. 


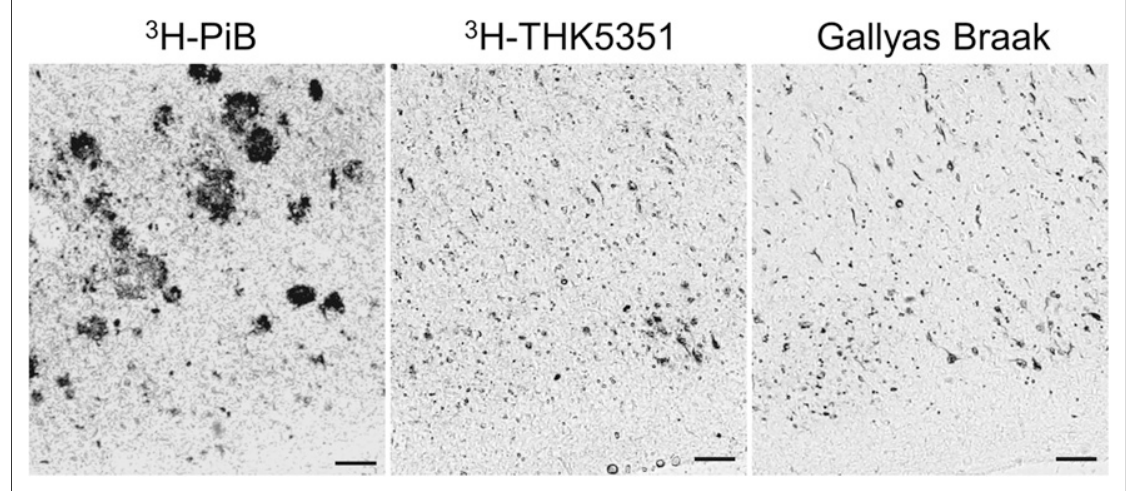

FIGURE 3. High-resolution autoradiography of ${ }^{3} \mathrm{H}-\mathrm{PiB}$ and ${ }^{3} \mathrm{H}-\mathrm{THK} 5351$ and Gallyas-Braak silver staining in entorhinal cortex of $A D$ patient.
${ }^{18} \mathrm{~F}-\mathrm{THK} 5351$ and ${ }^{18} \mathrm{~F}-\mathrm{THK} 5117$ retention was particularly prominent in the mesial temporal lobe and the lateral temporal cortex, which differed considerably from ${ }^{11} \mathrm{C}-\mathrm{PiB}$ retention in the same $\mathrm{AD}$ patient (Table 1): ${ }^{11} \mathrm{C}-\mathrm{PiB}$ exhibited extremely high retention throughout broad neocortical areas except for the mesial temporal lobe. The regional SUVRs of ${ }^{18} \mathrm{~F}$-THK5351 were higher than those of ${ }^{18} \mathrm{~F}-\mathrm{THK} 5117$ (Table 1), and the regional SUVRs of ${ }^{18} \mathrm{~F}$-THK5351 in 2 AD patients were significantly correlated with those of ${ }^{18} \mathrm{~F}-\mathrm{THK} 5117$ (Spearman $r=$ $0.839, P<0.001$ ) but not that of ${ }^{11} \mathrm{C}-\mathrm{PiB}$ (Fig. 7). noted in clinical observations, body weight measurement, and pathologic examination.

\section{Dose Estimates for Humans}

${ }^{18} \mathrm{~F}-\mathrm{THK} 5351$ radiation exposure was estimated using the biodistribution data from mice (Supplemental Table 2). The resultant whole-body effective dose equivalents were $14.4 \mu \mathrm{Sv} / \mathrm{MBq}$ (men) and $18.4 \mu \mathrm{Sv} / \mathrm{MBq}$ (women) (Supplemental Table 3). The organ doses for ${ }^{18} \mathrm{~F}$-THK5351 were comparable to those associated with other common radiotracers.

\section{Clinical PET Study}

The SUV time-activity curves from ${ }^{18} \mathrm{~F}-\mathrm{THK} 5351$ and ${ }^{18} \mathrm{~F}-$ THK5117 PET in 2 patients are shown in Figure 5. The pharmacokinetic data agreed with the small-animal PET study in normal mice. The peak uptake of ${ }^{18} \mathrm{~F}-\mathrm{THK} 5351$ was again slightly lower than that of ${ }^{18} \mathrm{~F}$-THK5117, but ${ }^{18} \mathrm{~F}$-THK5351 was cleared more rapidly than ${ }^{18} \mathrm{~F}-\mathrm{THK} 5117$ from the cerebellar cortex. In the AD patients, ${ }^{18} \mathrm{~F}$ THK5351 binding in the inferior temporal cortex exceeded whitematter binding at all the time points after injection.

PET images are shown in Figure 6. ${ }^{18}$ F-THK5351 retention in the temporal lobe clearly distinguished $\mathrm{AD}$ patients from healthy elderly participants, although mild ${ }^{18}$ F-THK5351 retention was observed in the medial temporal cortex of elderly healthy control subjects (Fig. 6A). ${ }^{18} \mathrm{~F}$-THK5351 showed higher contrast and lower subcortical white-matter retention than ${ }^{18} \mathrm{~F}$-THK5117 did (Fig. 6B).

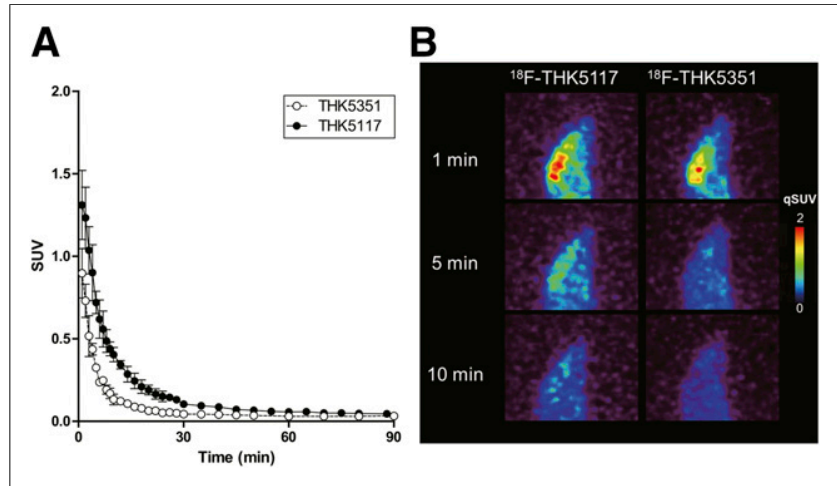

FIGURE 4. (A) Brain time-activity curves after intravenous administration of ${ }^{18} \mathrm{~F}$-THK5351 and ${ }^{18} \mathrm{~F}-$ THK5117 in normal mice $(n=4)$. (B) Representative PET images of ${ }^{18} \mathrm{~F}-$ THK5117 and ${ }^{18} \mathrm{~F}-$ THK5351 at 1,5 , and $10 \mathrm{~min}$ after injection in normal mice.

\section{DISCUSSION}

${ }^{18} \mathrm{~F}-\mathrm{THK} 5351$ is a single $S$-enantiomer and pyridine derivative of ${ }^{18} \mathrm{~F}$-THK5117, and ${ }^{18} \mathrm{~F}$-THK5351 is less lipophilic than ${ }^{18} \mathrm{~F}-\mathrm{THK} 5117$ ( $\log P=1.5$ vs. 2.32$)$. As observed with amyloid PET tracers, pyridine derivatives tend to show reduced lipophilicity, which correlates with the amount of nonspecific binding (26). Replacement of the 2-aryl group from the benzene to the pyridine ring might contribute to diminished nonspecific binding to subcortical white matter, as observed in the relationship between ${ }^{11} \mathrm{C}-\mathrm{PiB}$ and ${ }^{11} \mathrm{C}$-AZD2184 (27-29). Moreover, ${ }^{18} \mathrm{~F}-\mathrm{THK} 5351$ is optically pure, whereas ${ }^{18} \mathrm{~F}-\mathrm{THK} 5105$ and ${ }^{18} \mathrm{~F}$-THK5117 are racemic mixtures. Enantiomers frequently show differences in biologic properties such as
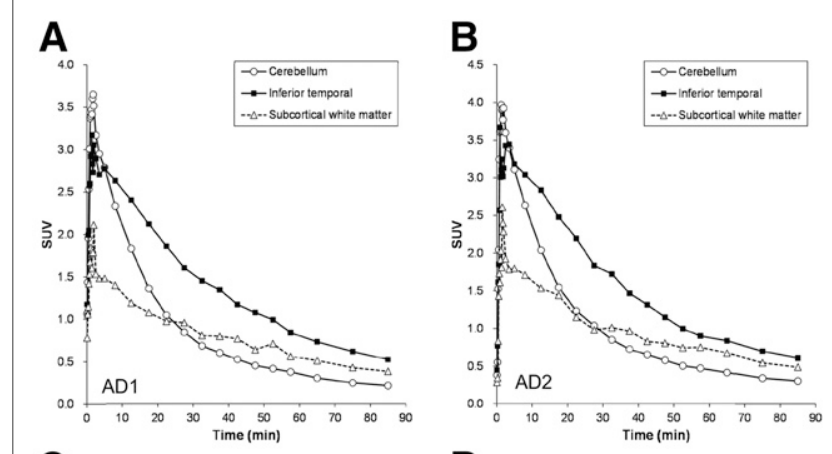

C
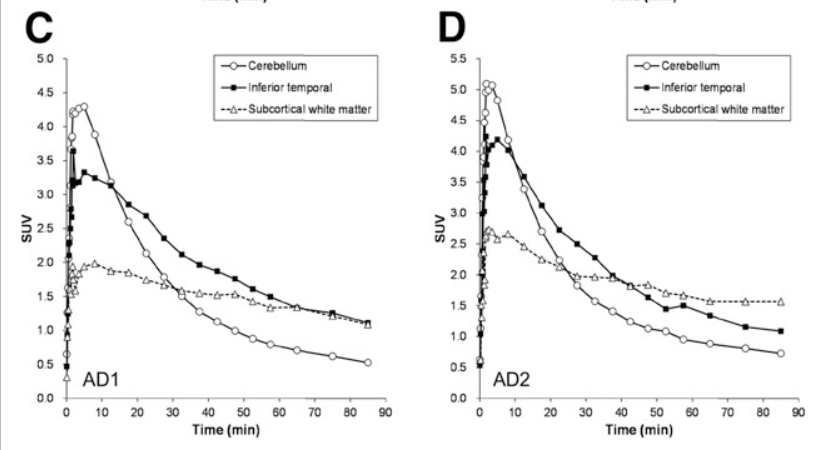

FIGURE 5. ${ }^{18} \mathrm{~F}-$ THK5351 (A and B) and ${ }^{18} \mathrm{~F}-\mathrm{THK} 5117$ (C and D) SUV time-activity curves in cerebellum (O), inferior temporal cortex ( $\square$ ), and subcortical white matter $(\triangle)$ of 2 AD patients (AD1: 88-y-old man, Mini Mental State Examination [MMSE] score of 25; AD2: 58-y-old man, MMSE score of 19). 


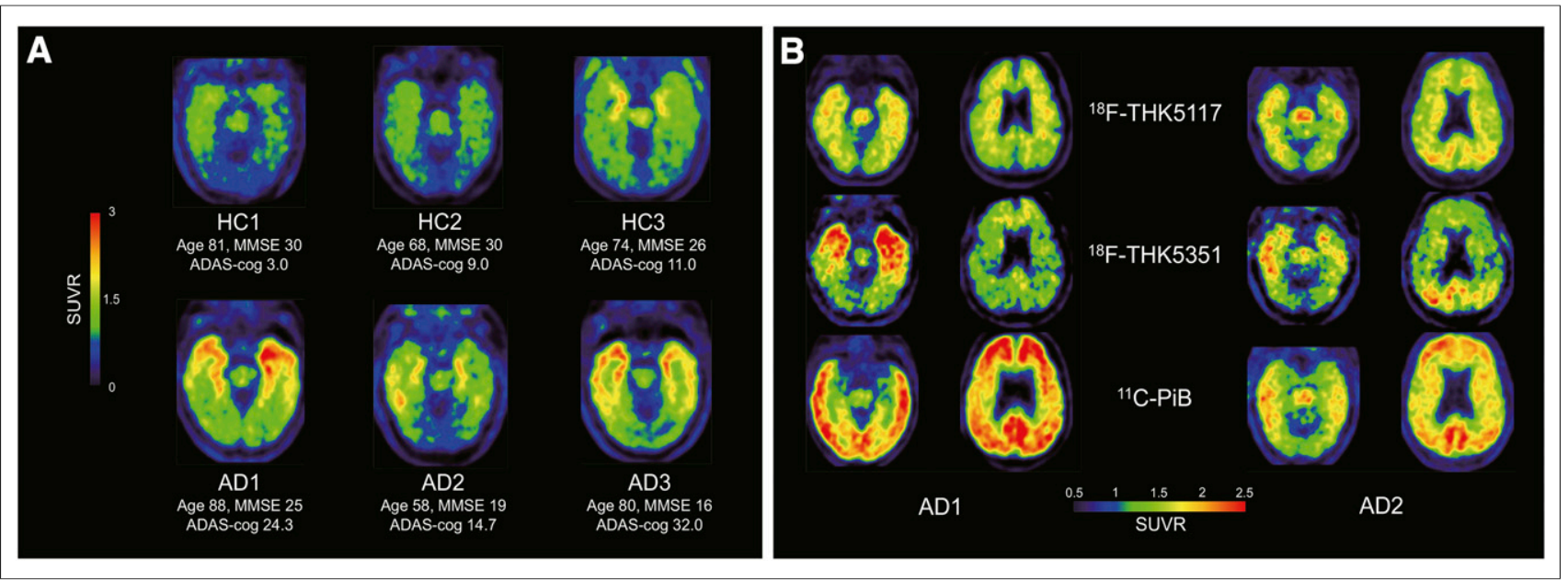

FIGURE 6. (A) SUVR images of ${ }^{18} \mathrm{~F}-\mathrm{THK} 5351$ PET from 40 to 60 min after injection in 3 healthy control (HC) participants and $3 \mathrm{AD}$ patients. (B) SUVR images of ${ }^{18} \mathrm{~F}$-THK5117 and ${ }^{18} \mathrm{~F}$-THK5351 PET from 50 to 60 min after injection and ${ }^{11} \mathrm{C}-\mathrm{PiB}$ PET from 40 to 70 min after injection in 2 AD patients (AD1: 88-y-old man, Mini Mental State Examination [MMSE] score of 25; AD2: 58-y-old man, MMSE score of 19).

metabolism or binding affinity for targets (30). Our preclinical studies demonstrated that the pharmacokinetic profiles of the $S$-enantiomers of arylquinoline derivatives were more favorable than those of the $R$-enantiomers $(20,24)$. Therefore, optical purification should additionally contribute toward improving THK5351 pharmacokinetics. Our preclinical data revealed that ${ }^{18} \mathrm{~F}$-THK5351 showed high and selective binding ability for tau aggregates, low binding affinity for white matter, and rapid pharmacokinetics, which collectively resulted in the signal-to-background ratio of THK5351 being higher than that of both THK5105 and THK5117. Furthermore, autoradiography performed on human brain sections also confirmed that THK5351 did not bind to amyloid, $\alpha$-synuclein, and TDP43 deposits (data not shown), suggesting that THK5351 binds to tau protein fibrils with high selectivity.

As observed in our previous ${ }^{18} \mathrm{~F}-\mathrm{THK} 5105$ and ${ }^{18} \mathrm{~F}-\mathrm{THK} 5117$ PET studies $(19,20),{ }^{18} \mathrm{~F}$-THK5351 retention was prominent in the temporal lobe of AD patients. This regional distribution of ${ }^{18} \mathrm{~F}-$ THK5351 in AD patients agreed with the postmortem observation that the temporal lobe was more susceptible to tau deposition than other cortical areas $(31,32)$. Although the cortical distributions of ${ }^{18} \mathrm{~F}$-THK5351 and ${ }^{18} \mathrm{~F}-\mathrm{THK} 5117$ in the same patients were almost identical, ${ }^{18}$ F-THK5351 displayed comparatively higher

\section{TABLE 1}

Regional SUVRs (50-60 Minutes After Injection) of ${ }^{18} \mathrm{~F}-\mathrm{THK} 5117,{ }^{18} \mathrm{~F}-\mathrm{THK} 5351$, and ${ }^{11} \mathrm{C}-\mathrm{PiB}$ in 3 Healthy Controls and $3 \mathrm{AD}$ Patients

\begin{tabular}{|c|c|c|c|c|c|c|c|c|c|c|}
\hline \multirow[b]{3}{*}{ Region } & \multirow{3}{*}{$\begin{array}{c}\text { Healthy } \\
\text { control } 1 \text {, } \\
{ }^{18} \text { F- } \\
\text { THK5351 }\end{array}$} & \multirow{3}{*}{$\begin{array}{c}\text { Healthy } \\
\text { control 2, } \\
{ }^{18} \mathrm{~F}- \\
\text { THK5351 }\end{array}$} & \multirow{3}{*}{$\begin{array}{c}\text { Healthy } \\
\text { control 3, } \\
{ }^{18} \text { F- } \\
\text { THK5351 }\end{array}$} & \multicolumn{3}{|c|}{ AD patient 1} & \multicolumn{3}{|c|}{ AD patient 2} & \multirow{2}{*}{$\begin{array}{c}\text { AD patient } 3, \\
18 \mathrm{~F}-\end{array}$} \\
\hline & & & & $18 \mathrm{~F}-$ & ${ }^{18} \mathrm{~F}-$ & ${ }^{11} \mathrm{C}-$ & $18 \mathrm{~F}-$ & ${ }^{18} \mathrm{~F}-$ & ${ }^{11} \mathrm{C}-$ & \\
\hline & & & & THK5351 & THK5117 & $\mathrm{PiB}$ & THK5351 & THK5117 & $\mathrm{PiB}$ & THK5351 \\
\hline $\begin{array}{l}\text { Dorsolateral } \\
\text { prefrontal }\end{array}$ & 1.16 & 1.15 & 1.36 & 1.46 & 1.23 & 2.19 & 1.46 & 1.26 & 2.10 & 1.81 \\
\hline $\begin{array}{c}\text { Ventrolateral } \\
\text { prefrontal }\end{array}$ & 1.28 & 1.19 & 1.35 & 1.93 & 1.51 & 3.11 & 1.70 & 1.37 & 2.41 & 2.03 \\
\hline Orbitofrontal & 1.08 & 1.16 & 1.45 & 1.80 & 1.39 & 2.64 & 1.51 & 1.22 & 2.20 & 1.59 \\
\hline Superior temporal & 1.36 & 1.55 & 1.51 & 1.88 & 1.49 & 2.55 & 1.80 & 1.56 & 2.00 & 1.67 \\
\hline Inferior temporal & 1.44 & 1.51 & 1.67 & 2.33 & 1.86 & 2.46 & 1.93 & 1.45 & 2.03 & 2.36 \\
\hline Parietal & 1.43 & 1.40 & 1.39 & 2.21 & 1.56 & 2.79 & 2.38 & 1.71 & 2.24 & 2.22 \\
\hline Occipital & 1.26 & 1.27 & 1.37 & 1.80 & 1.62 & 2.45 & 1.71 & 1.26 & 1.64 & 1.68 \\
\hline $\begin{array}{l}\text { Posterior } \\
\text { cingulate }\end{array}$ & 1.32 & 1.41 & 1.63 & 1.97 & 1.38 & 2.65 & 2.38 & 1.70 & 2.64 & 2.48 \\
\hline Anterior cingulate & 1.41 & 1.54 & 1.53 & 2.10 & 1.50 & 2.49 & 1.74 & 1.40 & 2.23 & 1.76 \\
\hline $\begin{array}{l}\text { Parahippocampal } \\
\text { gyrus }\end{array}$ & 1.85 & 1.92 & 2.03 & 2.66 & 1.59 & 1.51 & 2.32 & 1.66 & 1.97 & 1.82 \\
\hline Hippocampus & 1.96 & 2.03 & 2.44 & 3.17 & 1.71 & 1.17 & 2.49 & 1.64 & 1.33 & 3.28 \\
\hline $\begin{array}{l}\text { Subcortical white } \\
\text { matter }\end{array}$ & 1.42 & 1.36 & 1.60 & 1.61 & 1.65 & 1.81 & 1.52 & 1.66 & 2.16 & 1.38 \\
\hline
\end{tabular}




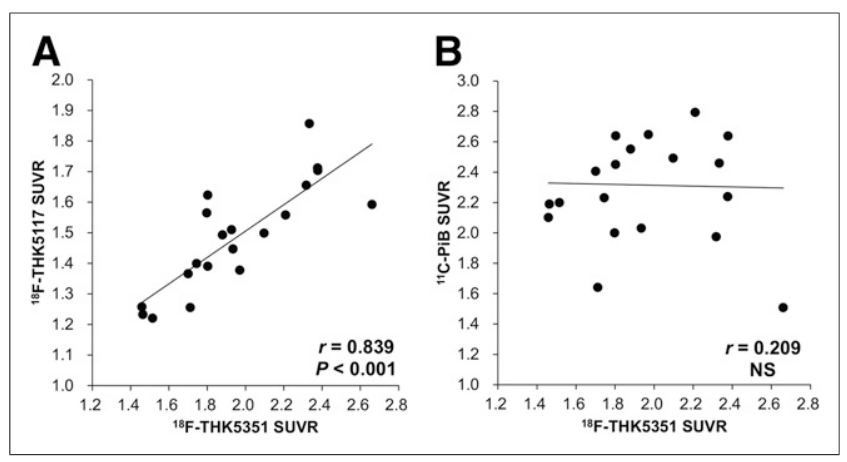

FIGURE 7. Correlation between regional SUVR of ${ }^{18} \mathrm{~F}-\mathrm{THK} 5351$ and ${ }^{18} \mathrm{~F}-$ THK5117 (Spearman $r=0.839, P<0.001$ ), but not ${ }^{18} \mathrm{~F}-\mathrm{THK} 5351$ and ${ }^{11} \mathrm{C}$-PiB $(r=0.209$, not significant [NS]), in 2 AD patients.

contrast and lower subcortical white-matter retention; this is strikingly similar to our preclinical findings (Figs. 2-4). When compared with reported tau radiotracers such as ${ }^{11} \mathrm{C}-\mathrm{PBB} 3$ and ${ }^{18} \mathrm{~F}-\mathrm{T} 807$, a drawback of ${ }^{18} \mathrm{~F}$-THK5117 is high white-matter retention, which is frequently observed with ${ }^{18} \mathrm{~F}$-labeled amyloid radiotracers (33). The cortical-to-white matter ratio of ${ }^{18}$ F-THK5351 in AD patients was substantially higher than that of ${ }^{18} \mathrm{~F}$-THK5117, which allows comparatively easier and more accurate visual interpretation of PET images. No remarkable retention of ${ }^{18} \mathrm{~F}$-THK5351 was observed in the choroid plexus or venous sinus. This is one of the advantages over the other tau tracers, because off-target retention in these areas might cause a spill-in of the tracer signals into the brain. However, as observed with other radiotracers, offtarget binding of ${ }^{18} \mathrm{~F}-\mathrm{THK} 5351$ was detected in the basal ganglia; the binding target of THK5351 in this region should be clarified in future studies. Moreover, ${ }^{18} \mathrm{~F}-\mathrm{THK} 5351$ must be directly compared with other tau radiotracers to characterize the binding property of each radiotracer and to determine how their differences affect the accuracy of visual interpretation and the sensitivity for detecting subtle changes in brain tau loads over time, as done in the case of amyloid radiotracers (34-36). Furthermore, imagingautopsy studies are required to validate the described binding selectivity in the future.

\section{CONCLUSION}

${ }^{18} \mathrm{~F}-\mathrm{THK} 5351$ selectively bound to pathologic tau deposits in postmortem AD brain tissues but showed weak white-matter binding. Fast pharmacokinetics, high contrast, and low white-matter retention of ${ }^{18} \mathrm{~F}$-THK5351 allow sensitive detection of tau pathology in humans, which could facilitate early detection and longitudinal assessment of neurofibrillary pathology.

\section{DISCLOSURE}

The costs of publication of this article were defrayed in part by the payment of page charges. Therefore, and solely to indicate this fact, this article is hereby marked "advertisement" in accordance with 18 USC section 1734 . This study was supported by research funds from GE Healthcare; the SEI (Sumitomo Electric Industries, Ltd.) Group CSR Foundation; the Industrial Technology Research grant program of the NEDO in Japan (09E51025a); Health and Labor Sciences Research grants from the Ministry of Health, Labor, and Welfare of Japan; grant-in-aid for Scientific Research (B)
(15H04900); grant-in-aid for Scientific Research on Innovative Areas (Brain Protein Aging and Dementia Control) (26117003); grant-in-aid for Young Scientists (B) (15K19767); and grant-in-aid for JSPS Fellows and "Japan Advanced Molecular Imaging Program (J-AMP)" of the Ministry of Education, Culture, Sports, Science and Technology (MEXT), Japan. No other potential conflict of interest relevant to this article was reported.

\section{REFERENCES}

1. Braak H, Braak E. Neuropathological stageing of Alzheimer-related changes. Acta Neuropathol (Berl). 1991;82:239-259.

2. Braak E, Braak H, Mandelkow EM. A sequence of cytoskeleton changes related to the formation of neurofibrillary tangles and neuropil threads. Acta Neuropathol (Berl). 1994;87:554-567.

3. Braak H, Alafuzoff I, Arzberger T, Kretzschmar H, Del Tredici K. Staging of Alzheimer disease-associated neurofibrillary pathology using paraffin sections and immunocytochemistry. Acta Neuropathol (Berl). 2006;112:389-404.

4. Delacourte A, David JP, Sergeant N, et al. The biochemical pathway of neurofibrillary degeneration in aging and Alzheimer's disease. Neurology. 1999;52: 1158-1165.

5. Guillozet AL, Weintraub S, Mash DC, Mesulam MM. Neurofibrillary tangles, amyloid, and memory in aging and mild cognitive impairment. Arch Neurol. 2003;60:729-736.

6. Brunden KR, Trojanowski JQ, Lee VM. Advances in tau-focused drug discovery for Alzheimer's disease and related tauopathies. Nat Rev Drug Discov. 2009;8: 783-793.

7. Giacobini E, Gold G. Alzheimer disease therapy-moving from amyloid- $\beta$ to tau. Nat Rev Neurol. 2013;9:677-686.

8. Okamura N, Harada R, Furumoto S, Arai H, Yanai K, Kudo Y. Tau PET imaging in Alzheimer's disease. Curr Neurol Neurosci Rep. 2014;14:500.

9. Villemagne VL, Fodero-Tavoletti MT, Masters CL, Rowe CC. Tau imaging: early progress and future directions. Lancet Neurol. 2015;14:114-124.

10. Ariza M, Kolb HC, Moechars D, Rombouts F, Andres JI. Tau positron emission tomography (PET) imaging: past, present, and future. J Med Chem. 2015;58:43654382.

11. Chien DT, Bahri S, Szardenings AK, et al. Early clinical PET imaging results with the novel PHF-tau radioligand [F-18]-T807. J Alzheimers Dis. 2013;34:457-468.

12. Chien DT, Szardenings AK, Bahri S, et al. Early clinical PET imaging results with the novel PHF-tau radioligand [F18]-T808. J Alzheimers Dis. 2014;38:171184.

13. Maruyama M, Shimada H, Suhara T, et al. Imaging of tau pathology in a tauopathy mouse model and in Alzheimer patients compared to normal controls. Neuron. 2013;79:1094-1108.

14. Villemagne VL, Furumoto S, Fodero-Tavoletti MT, et al. In vivo evaluation of a novel tau imaging tracer for Alzheimer's disease. Eur J Nucl Med Mol Imaging. 2014;41:816-826.

15. Okamura N, Suemoto T, Furumoto S, et al. Quinoline and benzimidazole derivatives: candidate probes for in vivo imaging of tau pathology in Alzheimer's disease. J Neurosci. 2005;25:10857-10862.

16. Fodero-Tavoletti MT, Okamura N, Furumoto S, et al. ${ }^{18} \mathrm{~F}-\mathrm{THK} 523$ : a novel in vivo tau imaging ligand for Alzheimer's disease. Brain. 2011;134:10891100 .

17. Harada R, Okamura N, Furumoto S, et al. Comparison of the binding characteristics of $\left[{ }^{18} \mathrm{~F}\right] \mathrm{THK}-523$ and other amyloid imaging tracers to Alzheimer's disease pathology. Eur J Nucl Med Mol Imaging. 2013;40:125-132.

18. Okamura N, Furumoto S, Harada R, et al. Novel ${ }^{18} \mathrm{~F}$-labeled arylquinoline derivatives for noninvasive imaging of tau pathology in Alzheimer disease. $\mathrm{J} \mathrm{Nucl}$ Med. 2013;54:1420-1427.

19. Okamura N, Furumoto S, Fodero-Tavoletti MT, et al. Non-invasive assessment of Alzheimer's disease neurofibrillary pathology using ${ }^{18} \mathrm{~F}-\mathrm{THK} 5105$ PET. Brain. 2014;137:1762-1771.

20. Harada R, Okamura N, Furumoto S, et al. [ $\left.{ }^{18} \mathrm{~F}\right] \mathrm{THK}-5117$ PET for assessing neurofibrillary pathology in Alzheimer's disease. Eur J Nucl Med Mol Imaging. 2015;42:1052-1061.

21. Kuzuhara S, Ihara Y, Toyokura Y, Shimada H. A semiquantitative study on Alzheimer neurofibrillary tangles demonstrated immunohistochemically with antitau antibodies, in the brains of non-demented and demented old people [in Japanese]. No To Shinkei. 1989;41:465-470. 
22. Morris JC, Price JL. Pathologic correlates of nondemented aging, mild cognitive impairment, and early-stage Alzheimer's disease. J Mol Neurosci. 2001;17: 101-118.

23. Crary JF, Trojanowski JQ, Schneider JA, et al. Primary age-related tauopathy (PART): a common pathology associated with human aging. Acta Neuropathol (Berl). 2014;128:755-766.

24. Tago T, Furumoto S, Okamura N, et al. Preclinical evaluation of $\left[{ }^{18} \mathrm{~F}\right] \mathrm{THK}-5105$ enantiomers: effects of chirality on its effectiveness as a tau imaging radiotracer. Mol Imaging Biol. In press.

25. Verdurand M, Bort G, Tadino V, Bonnefoi F, Le Bars D, Zimmer L. Automated radiosynthesis of the Pittsburg compound-B using a commercial synthesizer. Nucl Med Commun. 2008;29:920-926.

26. Forsberg A, Jureus A, Cselenyi Z, et al. Low background and high contrast PET imaging of amyloid- $\beta$ with $\left[{ }^{11} \mathrm{C}\right] \mathrm{AZD} 2995$ and $\left[{ }^{11} \mathrm{C}\right] \mathrm{AZD} 2184$ in Alzheimer's disease patients. Eur J Nucl Med Mol Imaging. 2013;40:580-593.

27. Klunk WE, Engler H, Nordberg A, et al. Imaging brain amyloid in Alzheimer's disease with Pittsburgh compound-B. Ann Neurol. 2004;55:306-319.

28. Nyberg S, Jonhagen ME, Cselenyi Z, et al. Detection of amyloid in Alzheimer's disease with positron emission tomography using $\left[{ }^{11} \mathrm{C}\right] \mathrm{AZD} 2184$. Eur J Nucl Med Mol Imaging. 2009;36:1859-1863.
29. Johnson AE, Jeppsson F, Sandell J, et al. AZD2184: a radioligand for sensitive detection of $\beta$-amyloid deposits. J Neurochem. 2009;108:1177-1186.

30. Simonyi M, Fitos I, Visy J. Chirality of bioactive agents in protein-binding storage and transport processes. Trends Pharmacol Sci. 1986;7:112-116.

31. Wilcock GK, Esiri MM. Plaques, tangles and dementia: a quantitative study. J Neurol Sci. 1982;56:343-356.

32. Arnold SE, Hyman BT, Flory J, Damasio AR, Van Hoesen GW. The topographical and neuroanatomical distribution of neurofibrillary tangles and neuritic plaques in the cerebral cortex of patients with Alzheimer's disease. Cereb Cortex. 1991;1:103-116.

33. Rowe CC, Villemagne VL. Brain amyloid imaging. J Nucl Med. 2011;52:1733-1740.

34. Villemagne VL, Mulligan RS, Pejoska S, et al. Comparison of ${ }^{11} \mathrm{C}-\mathrm{PiB}$ and ${ }^{18} \mathrm{~F}-$ florbetaben for A $\beta$ imaging in ageing and Alzheimer's disease. Eur J Nucl Med Mol Imaging. 2012;39:983-989.

35. Wolk DA, Zhang Z, Boudhar S, Clark CM, Pontecorvo MJ, Arnold SE. Amyloid imaging in Alzheimer's disease: comparison of florbetapir and Pittsburgh compound-B positron emission tomography. J Neurol Neurosurg Psychiatry. 2012;83:923-926.

36. Rowe CC, Pejoska S, Mulligan RS, et al. Head-to-head comparison of ${ }^{11} \mathrm{C}-\mathrm{PiB}$ and ${ }^{18} \mathrm{~F}$-AZD4694 (NAV4694) for $\beta$-amyloid imaging in aging and dementia. J Nucl Med. 2013;54:880-886. 